\title{
Lessons Learned in Afghanistan: A Multi-national Military Mental Health Perspective
}

\author{
Randall C. Nedegaard \\ Rachel E. Foster \\ Mercy Yeboah-Ampadu \\ Andrew J. Stubbs
}

\begin{abstract}
America has been at war for almost 10 years. Because of this, continuing missions in the Middle East require the support and cooperation of our allied North Atlantic Treaty Organization (NATO) forces from around the world. In this paper we provide an overview of the mission at Kandahar Air Field (KAF) and the Multi-National Role 3 hospital located at KAF. Next, we explain the mental health capabilities and unique perspectives among our teammates from Canada, Great Britain, and the United States to include a discussion of the relevant cross-cultural differences between us. Within this framework we also provide an overview of the mental health clientele seen at KAF during the period of April 2009 through September 2009. Finally, we discuss the successes, limitations, and lessons learned during our deployment to Kandahar, Afghanistan.
\end{abstract}

Keywords: Multi-national, military, mental health, deployment

\section{INTRODUCTION}

America has been at war for almost 10 years. Shortly after the attacks on the United States on September $11^{\text {th }}$, 2001, Operation Enduring Freedom (OEF) began on October 7, of that same year. This started with aerial bombings in Afghanistan by American and British forces in an attempt to end worldwide terrorism. In December 2001 the United States (US) and her allies (specifically the United Kingdom, Germany, and the Northern Alliance) had received intelligence reports that the leader of terrorist operations, Osama bin Laden, was directing operations from the rugged mountains of Tora Bora in the Nangarhar Province of Afghanistan. Efforts to capture Osama were lost despite the battle waged there.

On March 2, 2002, the US Military and other countries that comprise the North Atlantic Treaty Organization (NATO), to include the Afghan National Army, Canada, United Kingdom, Germany, France, Australia, New Zealand, Norway, and Denmark launched Operation Anaconda in an attempt to destroy al-Qaeda and Taliban forces in the Shahi-Kot Valley of the Paktia Province of Afghanistan. Operation Anaconda ended on

\footnotetext{
Randall C. Nedegaard, Ph.D., (retired Lieutenant Colonel USAF) is an Assistant Professor, Department of Social Work, University of North Dakota. Major Rachel E. Foster, Ph.D., is a United States Air Force Officer, Clinical Social Work, stationed at Joint Base Anacostia-Bolling, Washington, DC. Lieutenant Commander Mercy Yeboah-Ampadu, MSc.SS, RSW, is a Senior Social Work Officer in the Canadian Forces stationed at Canadian Forces Base Edmonton. Captain Andrew J. Stubbs, RMN, Dip MH, BSc (Hons), is a British Army Mental Health Officer based at Queen Elizabeth Barracks, Strensall, York, England. The opinions expressed in this article are the authors' and should not be interpreted as the policy or opinions of the United States Air Force, Canadian Forces, or the British Army.
} 
March 16, 2002 with reports of over 500 Taliban forces killed. Despite this, Osama bin Laden continued to evade capture.

Soon after these initial conflicts with Afghanistan, the US presidential administration under George W. Bush, along with the United Kingdom (UK), launched Operation Iraqi Freedom (OIF) on March 20, 2003. These countries shifted their focus to Iraq based on their suspicions of that country's involvement of employing weapons of mass destruction. After capturing the president of Iraq, Saddam Hussein, and charging him with war crimes, NATO turned its attention to securing Iraq as a free democracy. Eight years later, US President Barrack Obama renamed this initiative Operation New Dawn to reflect the ongoing withdrawal of NATO's military presence in Iraq.

Despite the drawdown of OIF, OEF continues. As part of OEF, Kandahar Airfield (KAF), which was once controlled by Taliban Forces, is now a NATO base. The primary mission of the NATO forces is called International Security Assistance Force (ISAF). True to the original intent of 9/11, ISAFs goal is to help build a democratic and free Afghanistan that is devoid of oppression and terrorism. Multiple OEF operations are based out of KAF and over 45 countries are represented there. It is at Kandahar, and the surrounding Forward Operating Bases (FOBs) and Combat Outposts (COPs) near Kandahar, that represent the focus of our work for this paper.

\section{KANDAHAR AIR FIELD}

NATO has divided Afghanistan into four regional commands. Regional commands North, South, East, and West. Kandahar Airfield (KAF) is the headquarters for Regional Command - South (RC-S). Our team was deployed together at Kandahar in the summer and fall of 2009 and was responsible for nearly all mental health support in RC-S. In the summer of 2009, there were only 1-2 more military mental health providers mobilized in RC-S with their respective military units in order to provide services to those specific units. This was during the time of a massive US troop build-up in Afghanistan that started in the spring of 2009. According to ISAF statistics, the approximate RC-S troop strength in April 2009 was 22,830 (ISAF, 2011). This NATO troop strength was more than doubled in less than one year. ISAF reported a RC-S troop strength of 45,100 in February 2010. Deployment of the medical and mental health assets needed to support this burgeoning troop population originally lagged behind, leading to significant increases in workload. Productivity in terms of medical and mental health encounters was at an alltime high for OEF, leaving the medical services in place to shoulder the additional burden until reinforcements could arrive.

\section{KANDAHAR ROLE 3 HOSPITAL}

There are four levels of medical care that wounded soldiers may receive from their time in the battlefield, all the way home to their respective countries. NATO has a developed common system of identification that assigns medical treatment facilities, or 'Roles,' that correspond with the levels of medical care each provides (Department of National Defence Canada, 2010). Role 1 medical facilities provide primary health care to include services in specialized first aid, triage of casualties, resuscitation, and 
stabilization. Role 2 medical facilities have the capacity to provide a higher level of treatment and care than the Role 1. Role 3 medical facilities are trauma level hospitals located in the deployed setting. They offer primary care services, surgical facilities, intensive care units, medical-surgical wards, diagnostic support and other in/outpatient services such as pharmacy, dental clinics, mental health services, and physical therapy. This was the case of the Role 3 Multinational Medical Unit at KAF (Role 3 MMU) during the time of our deployment in 2009. Role 4 medical facilities provide a broad spectrum of medical care and cannot be deployed in a combat theatre such as a local hospital found in most Western nations. If required, soldiers are evacuated to Role 4 medical facilities to their home nations.

The Role 3 MMU is organized into four components: (a) in-patient care; (b) clinical support; (c) primary care; and (d) administration. In-patient care is composed of the operating room, an intensive care unit, trauma bays, and the acute care ward. Mental health services, pharmacy, x-ray, and laboratory services falls under clinical support. Primary care was responsible for physical therapy, dental services, preventive medicine, and the unit medical services.

From 2006 to October 2009 Canada was the lead nation commanding the Role 3 MMU at the KAF. During this time period the Role $3 \mathrm{MMU}$ treated over 42,000 patients, performing an estimated 4,500 surgeries and admitting more than 3,600 patients (Department of National Defence Canada, 2010). The Role 3 MMU provided care to NATO forces, Afghan security forces as well as to civilian contract employees and local nationals who had been injured as result of the conflict. The most unique aspect of the Role 3 MMU was its multinational workforce. Medical personnel, allied health professionals, and support staff from Canada, US, UK, New Zealand, Australia, Germany, Denmark, and the Netherlands ensured the highest levels of care to patients (Department of National Defence Canada, 2009).

\section{MENTAL HEALTH CAPABILITIES AT KANDAHAR}

Kandahar is the transportation hub of RC-S. Most fixed wing aircraft and rotary (helicopter) flying was done between Kandahar and the outlying FOBs or COPs. When a soldier needed the care of a mental health professional, they had the option of being flown into KAF if space was available. Otherwise, their unit leadership could call the mental health providers at the Role 3 to request that someone come to their location and provide services for their troops. This could be problematic, because it might take a soldier upwards of one week to fly from their location to Kandahar, get the short-term mental health support they needed, and return to their unit. Our team experienced similar travel challenges when we went to the FOBs as these trips averaged a minimum of 3 days or more, leaving the Role 3 mental health team back at KAF to cover the workload short staffed.

Mental health care has been an integral part of medical care provided at the Role 3 MMU KAF. The mental health department was designated as an outpatient service under primary care. Despite this, it offered 24-hour services as mandated by the Role $3 \mathrm{MMU}$ KAF mission. The permanent team consisted of four Canadian mental health clinicians; 
one civilian psychiatrist, one senior social work officer, one junior social work officer and one mental health nurse officer. Additionally, one Mental Health Nurse officer from the UK was assigned to the Role 3 MMU. Finally, a Combat Stress Control (CSC) team from the US Air Force was attached (lended) to the Role $3 \mathrm{MMU}$ and included either a social work officer or a psychologist officer and a mental health technician. This small team was responsible for the provision of mental health care for an expanding population of over 25,000 people at KAF and to Canadian Forces located at FOBs. Together, the mental health providers were able to form a cohesive team and pool resources to provide a high quality of mental health care to service users of all nationalities who spoke English or French.

The US is unique in that it employs mental health technicians. These are enlisted members of the armed forces who are not required to have any formal training in mental health before they enlist in the military. They are sent to a mental health technical school training program after they complete basic training and receive a great deal of on-the-job training at their respective bases of assignment once they complete technical school. In essence, they are provider extenders and supporters. The US teams typically deploy mental health technicians with their mental health providers so that there are one or two technicians supporting each provider. Because this model is somewhat unique within NATO, Canadian and British providers needed to be trained as to how best to utilize the support of US mental health technicians.

\section{CHALLENGES UNIQUE TO THE INTERNATIONAL ENVIRONMENT}

Each country also has a unique approach to deployed mental health care and this created challenges for the team when treating members from another country. For example, there were vastly different standards for repatriation of military members depending on the country. This was a particular challenge for the team when, for example, a significant number of Canadian soldiers whom the team treated did not meet the Canadian standard for deployment fitness according to our psychiatrist but were denied repatriation home because they were commanded by US officers who applied a US treatment philosophy to these situations. In the Canadian Forces, a recommendation by a psychiatrist or a physician was normally accepted and substantiated by the Senior Medical Advisor who advises command. This routinely leads to final approval by the Joint Task Force Commander and the soldier was medically repatriated. This difference in policy among the various countries meant that the mental health team had to manage more clients with poor functioning and/or chronic, severe mental health issues than the team was designed and trained for. This forced a focus on symptom management rather than problem resolution when dealing with long-term clientele, further compelling the team to provide on-going care as needed rather than engage the brief therapy models that are more widely embraced by the Canadian and British military forces. This approach was selected largely because most US military members were going to remain in theatre for extended periods of time and many adjustment problems, family challenges and even some mood disorders such as depression would not completely resolve themselves unless they returned home. 
Confidentiality was also a challenge in this international environment. For example, patient information is deemed confidential and is protected under federal legislation for the Canadian Forces. The only information that can be communicated to Commanding Officers are the soldier's employment limitations (e.g., cannot lift more than 151 bs x 10 days). Any other medical or social work information requires the expressed voluntary written consent of the member and the member can refuse to sign consent. The non-US members of our mental health team were challenged by being required to comply with a US Uniformed Code of Military Justice (UCMJ) they were unfamiliar with. The disclosure of drug use, homosexual orientation, and other violations of the UCMJ had to be disclosed to their command and the member could be reprimanded as was indicated on the US consent to treatment forms that were used for all US Forces. In Canada, the disclosure of such information during the therapeutic process is protected and only discussed with the medical team that places members on employment restrictions as needed. Obliging mental health clinicians to violate patient trust by disclosing information communicated in therapeutic setting with the potential of punishment is viewed as contrary to the goals of the therapeutic process and professional standards of mental health practice. This is in no way a criticism of US military policies, rather a demonstration of the different needs of each military organization and their requirements and the challenges of working with other nations in a multinational context.

Deployment screening criteria is also different among NATO countries. This is true among the US forces (Army, Air Force, Navy, and Marines) as well, adding to the complexity of how many mental health needs a particular military member can have and still remain deployed. These differences create diverse and layered complexities in terms of expectations and diagnosis for military members in which the multinational team had to navigate. For example, US soldiers with Attention Deficit Hyperactivity Disorder taking prescribed medication for their condition is something that would likely disqualify Canadian or British forces from military service.

The stigma associated with mental health services is a problem for members of all military services, despite the country of origin. Interestingly, stigma did not appear to be as problematic for the American soldiers seen at the Role 3 and they seemed to be more willing to engage in mental health work than the Canadian or British. The British are working hard to eliminate stigma and the Trauma Risk Management program supports lowering stigma, but we speculate that, as a nation, the British have not embraced 'therapy' in the same way the Americans have and an element of 'stiff upper lip' still remains.

A further difficulty was that the British forces were only seen by their own mental health team, which caused a splitting of time between the NATO work in the Role 3 and the duties to see the British forces mainly at the British Role 1 facility for the British provider. The British deploy three mental health nurses to cover the needs of a British deployed population of between 8,000 and 10,000. British mental health nurses are expected to pay 'house calls' to the Royal Air Force Regiment who guarded KAF, and the Black Watch Regiment who were stationed at KAF. A further duty was to attend to the troops in Kabul, which was some 300 miles away, as well as briefings for all troops coming into theatre and going home. The primary mental health philosophy of the British 
Forces is known as Trauma Risk Management (TRiM). TRiM is a system first used by the Royal Marines and is now well embedded into the British fighting operations (Frappell-Cooke, Gulina, Green, Hacker-Hughes, \& Greenberg, 2010). TRiM is a system of peer-support that operates through trained personnel within operational units who are trained to recognize psychological issues and facilitate social support (Greenberg, Langston, Everitt, Iversen, Fear, Jones, \& Wessley, 2010). This allows for mental health care to be assessed and in part delivered without the need for professional mental health practitioners to be present. If a need arises then the TRiM personnel can contact the British Field Mental Health Team for support. Further to this system, the treatment options for the British are different from the US and Canadian models. Within the NATO mental health team there was a facility for the US and Canadian troops to have access to a psychiatrist and the possibility of a number of different medications to be prescribed. This was not the case for the British forces as they cannot be in theatre with prescribed medication for mental health issues. This left the UK with limited treatment options and the use of short-term therapy, some very limited sleeping medication or just rest and 'watchful waiting' could be used before the patient would be repatriated for treatment back in the UK.

The US employs a philosophy of providing services as far forward as possible, enabling combat assets to remain in theater as long as possible and hopefully to complete their deployment and redeploy back home with their respective units. This philosophy is markedly different than other NATO countries. When we combine this with the fact that the US had roughly 50\% (ISAF, 2011) of the combat troops in ISAF in 2009, this leads to an inordinate number of US troops being served in theatre as is evidenced by the figures above. This began to overwhelm NATO mental health care resources as these countries had only deployed the assets they needed for their military populations given their treatment philosophies. This had the possibility of building resentment as these NATO providers ended up having very limited time to service troops from their own countries.

Similar to the US and UK approaches, Canada uses the general principles of proximity, immediacy, and expectancy (PIE) to treat other mental health and psychosocial presentations. The PIE approach was designed to reduce the soldier's sense of having to escape fighting and return home. Thus the proximity of care was close to the battle lines. Staying close to the battle lines allowed the soldier to stay in contact with their unit and maintain a sense of belonging and cohesiveness with their unit; a vital element in mission effectiveness. Symptoms are normalized and treatment is immediate to reduce the development of, or the long-term effects of symptoms. During the time of treatment, the soldier received constant reassurance and communication from the medical providers, the chain of command, and their fellow soldiers that there was an expectancy of recovery and return to work.

Consistent with the principles of PIE, the Canadian Forces (CF) approach to mental health is the preservation of personnel and support to families through early intervention, use of chaplain and social work services, and use of family support services on bases and in the community. However, in a combat zone such as Afghanistan, the resources available to mental health clinicians and medical staff are limited. As a result, there is much less flexibility in the intensity and duration of care compared to what can be 
provided at home bases. Therefore, the Canadian approach to mental health care is brief intervention. Service personnel who require more psychiatric care or psychosocial services and could not be returned to duty within a specific number of days were normally repatriated home through the medical chain of command. This was because a replacement had to be notified and deployed in a way that caused least disruption to the mission. Each deployed unit has a reserve of personnel who can replace most occupations. There were only a handful of jobs for which no replacements were available.

Due to the small size of the Canadian Forces (CF) and the integrated nature of its elements under one umbrella or force, most clinicians are able to forge relationships with the multiple command levels and their respective leaders of the deployed Battle Group. This close working relationship facilitated open communication and problem solving as an early intervention in dealing with challenging Canadian soldiers seeking mental health care. This type of intervention is highly encouraged within the CF model of patient care as it reduces the numbers of mental health and psychosocial repatriation. It also reduces an adversarial stance between medical professionals and unit commanders and instead promotes a partnership that seeks to balance the needs of the member with the operational requirements. Communication with the medical chain and unit commanders is designed to be regular and consistent. In the CF it is extremely rare that a supervisor or commander will go against a medical recommendation or a well-substantiated social work recommendation that offers a clear a supportable plan as these decisions are often made after exhausting other alternatives. Medical and psychosocial fitness for deployment are constantly evaluated at each interview with the core principle of PIE underlying each intervention.

\section{OVERVIEW OF PATIENTS - WHO DID WE SEE}

Interestingly, combat stress reactions were not the predominant complaint among patients interviewed by the mental health team during the 2009 deployment. The majority of cases seen at the mental health clinic were related to depression and anxiety and adjustment issues related to military induced separations (Table 1) and the majority of cases were US soldiers as they constituted at least half of the fighting force and are deployed for the longest time (Table 2). 
Table 1. Mental Health Visits by Category (April 2009 - September 2009) in the Combined Role 3 Multinational Medical Unit

\begin{tabular}{|l|c|}
\hline Combat/Operational Stress & $\mathbf{1 3 5}(\mathbf{0 6 \% )}$ \\
\hline PTSD/ASD & $\mathbf{2 4 5 ( 1 1 \% )}$ \\
\hline Depression or Anxiety & $\mathbf{6 2 3 ( 2 8 \% )}$ \\
\hline Mental Health Issue Not Previously Specified & $\mathbf{1 1 1 ( 0 5 \% )}$ \\
\hline Stress or Adjustment Issues & $\mathbf{4 0 1 ( 1 8 \% )}$ \\
\hline Partner or Family Issue & $\mathbf{1 3 3 ( 0 6 \% )}$ \\
\hline Behavioral or Occupational Problem & $\mathbf{1 5 6}(\mathbf{0 7 \% )}$ \\
\hline Military Acute Concussion Evaluation & $\mathbf{1 3 1}(\mathbf{0 6 \% )}$ \\
\hline Brief Contact & $\mathbf{2 0 1}(\mathbf{0 9 \% )}$ \\
\hline Other & $\mathbf{8 9}(\mathbf{0 4 \% )}$ \\
\hline
\end{tabular}

Table 2. Mental Health Visits by Nation (April 2009 - September 2009) in the Combined Role 3 Multinational Medical Unit

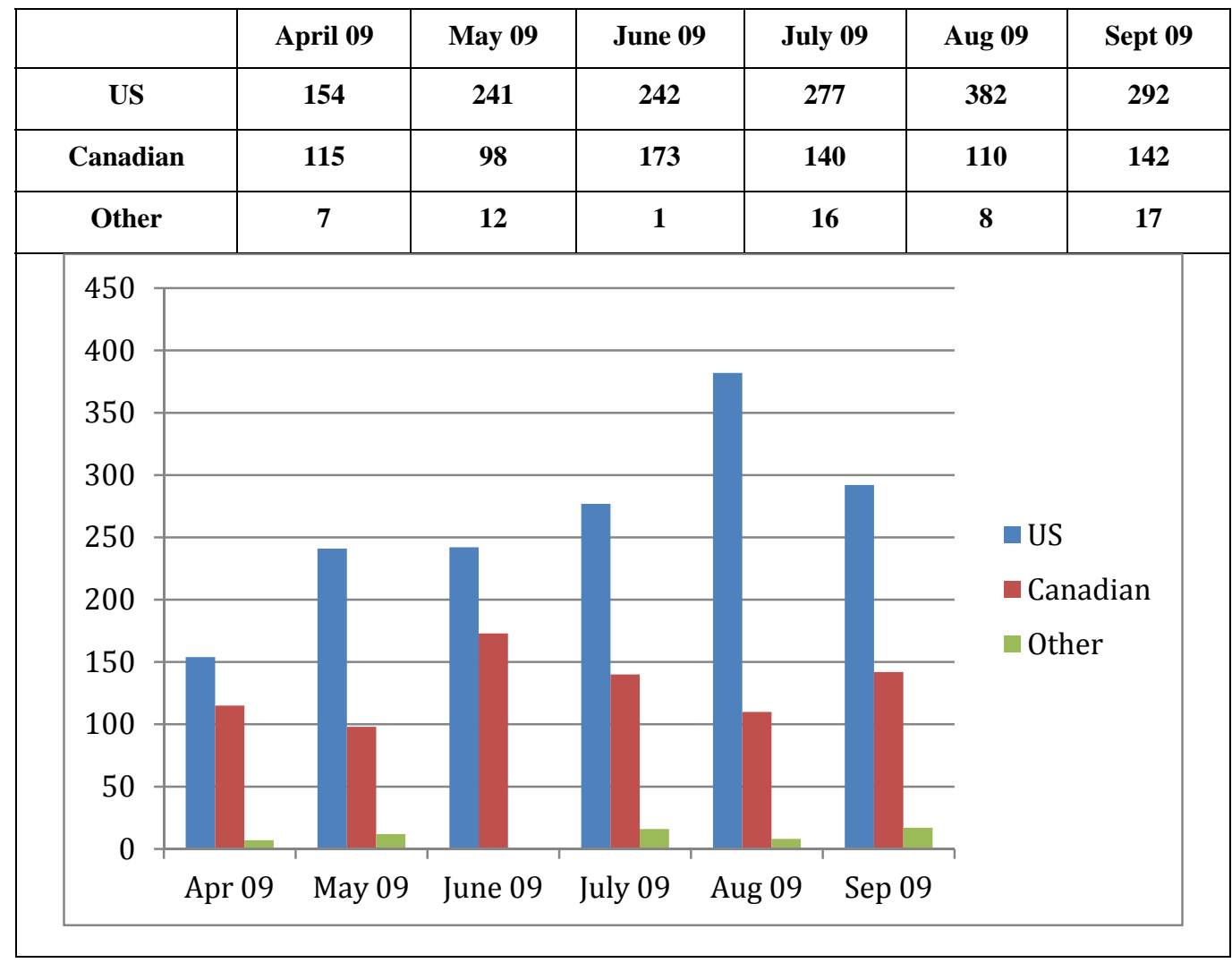




\section{LIMITATIONS OF THE TREATMENT ENVIRONMENT}

As with any deployed setting, there were natural limitations of the treatment environment. The immense heat of the summer in Southern Afghanistan makes for an oppressive setting. It also makes any kind of intervention very challenging to conduct outdoors if inside space is not available. As previously mentioned, space and a relative lack of privacy were often problematic and this was the case at the vast majority of military bases throughout Afghanistan. We also endured multiple rocket attacks. When rocket attacks occurred, the airfield was mostly shut down so that residents could shelter in bunkers to increase safety. This occurred during multiple sessions and was highly disruptive of not only that session, but of the appointment schedule overall.

Understandably, the Role 3 hospital at KAF was located directly next to the very busy flight line so that wounded troops could be transported as quickly as possible. Unfortunately, this meant that the noise level was frequently very loud and conducting interviews was challenging at those times. This location was also difficult to access for many of our patients who were stationed at Kandahar as the flight line is located near one edge of the airfield. Unlike the smaller FOBs and COPs, Kandahar is a vast base where transportation on the base is very limited. This meant that some of our patients would have to walk for more than an hour in intense heat just to be seen and served as a significant disincentive to seek care.

The final challenge/limitation of seeing patients in a combat environment has to do with carrying a weapon. US and Canadian forces are required to be armed at all times while deployed in order to support the defense of the base. Many times we would see troops who expressed significant suicidal and homicidal ideation and they would have their weapon on their person or right beside them. This occasionally led to some uncomfortable situations, especially considering the fact that a US Army soldier had been recently charged (May 2009) with killing five service people, two of which were mental health providers, after opening fire at a mental health facility in Iraq where he was being treated for combat stress. Later, concerns from patients were voiced about providers carrying weapons after the tragic Fort Hood shooting done by an army psychiatrist who was scheduled to deploy with a combat stress detachment to RC-S.

The rotating nature of deployment always is a challenge for continuity of care and team stability. Canadian military members have 6 month deployments with the exception of the contract psychiatrist who could work for as little as 3 months before returning home. British providers had 3-month deployments and the USAF deployments were 6 months. This created challenges in developing and maintaining a cohesive team, especially when you consider these deployments were staggered so the teams were normally consistent for the duration of a month or two.

\section{STRENGTHS AND SUCCESSES}

Our team was able to overcome many of the obstacles listed above and experienced several strengths and successes. We met every morning to coordinate the schedule and to discuss challenging cases. This helped to instill a common purpose of goals and mission for the team. We tried to help each other accomplish the mission, strengthening the team. 
If needed, we covered for each other, shared space, and tried to put the team in front of our personal needs. This increased morale and built cohesion. We also spent some time as a team while we were off duty, celebrating or relaxing together. The team had a broad range of experience and we shared this with one another. This occurred because we expressed interest and were willing to share the different points of view we had as a result of our differences in professional training, culture, and military experiences. Goodnatured teasing and competition based on these differences was evident throughout our time together. We were also fortunate enough to have a contract psychiatrist who was a retired officer in the Canadian forces so we had some common bonds in place as opposed to previous contract psychiatrists who had very limited experience with military members.

Perhaps one of the greatest successes was the productivity of the team. Productivity was arguably the highest it had ever been. In fact, it was 35\% larger (2225 contacts for Apr 09 - Sep 09) than the average of the previous two 6-month rotations (Apr 08 - Sep 08 $=1426$ and Oct 08 - Mar $09=1849$ ). Data was not available for rotations prior to April 2008. This sharp spike in the demand for services came as a result of RC-S absorbing a significant percentage of the large US troop surge that was ordered by the Obama Administration earlier that same year.

Because the deployment of mental health support services lagged behind this surge, we had to pull together as a team in order to manage this increased demand. Good communication and coordination of services was no longer a luxury, but a rather was a necessity. This resulted in better quality of care for our patients, more useful discussion about treatment options and, most importantly, a reduced wariness of our coalition forces patients to be treated by a provider not from one's own country. This was especially helpful for US troops, since the number of NATO mental health providers at Kandahar far outnumbered the available US mental health providers. This team focus also led to the admission of the first multi-national troop to the Freedom Restoration Center located in RC-East. This was the only restoration center in Afghanistan at the time and had served only US military personnel prior to this point. This program, run by the US Combat Stress Control Detachment at Bagram Airfield, is a 3-5 day program that gives service members a break from their stressful situations and return to their units more rested and better able to cope.

One of the main tests to the joint working environment came when there was a helicopter crash on the flight line killing 16 people and traumatizing many involved in the rescue effort. The base commander requested a response from the mental health team. The team facilitated visits to the fire service, ambulance service, and various personnel (both military and civilian) who witnessed this tragedy. Despite the fact that no precedent was in place for the team to follow for such an incident, our cohesion allowed us to quickly and decisively implement an effective plan, each member providing important contributions to our approach. For example, the UK provider noted that under the UK National Institute for Health and Clinical Excellence (NICE) guidelines, single incident debriefing was not indicated for this type of disaster and had the potential to make the situation worse (NICE, 2005). This recommendation was quickly adopted by the team and was incorporated into our response. 
All of these factors led to a more balanced effort on the part of the entire team and superseded insignificant issues such as who might be working harder, had better work space, or was a team player. The bonds developed in a period of two to three short months together led to lasting camaraderie post-deployment, as is evidenced by the combined authorship of this manuscript.

\section{LESSONS LEARNED}

Several lessons were learned from this experience, perhaps the most important being the value of putting aside differences in order to accomplish a larger goal of better service to our clientele. In order for coalition forces of any kind to be successful, the focus had to be on the larger team. Among the differences to be put aside are things like rank. Within the larger mental health team, rank has very little value. This is not to say that rank does not have a vital place within the context of the military, but in a setting like this one, it can create barriers. Large differences in rank can produce uneasiness and excessive formality within a military team and these barriers can take a great deal of time to overcome. In our situation, time was of the essence. Even the team leader worked to build consensus rather than be directive when this was possible.

Openness about differences proved to be vital as well. As a team, we needed to have a solid understanding of the differences in situation and philosophy for each of our members. By asking questions and honestly sharing our answers, there was an increased appreciation for the multiple roles we all had to play as well as a better understanding of the unique pressures we each faced within those roles. In social work education, we push our students to learn how to practice cultural competence and embrace the differences within the clients we serve. This situation required us to do that not just with our clients, but with our co-workers as well. Working together, we used each other's knowledge base as a pathway to cultural competence when treating service members from each other's country.

As an example of the unique pressures faced by team members, the British nurse at KAF had to juggle not only their time between duties to their own forces and the NATO command, but also toward the different treatment options of the NATO forces and two sets of paper work from the Canadian command and the British patients. Tensions could have easily existed with this 'splitting' of roles and countries philosophies towards the care of the troops. However, this was not the case for this deployment team. The unified goal for the team was focused on getting the best treatment we could to the patients rather than pursuing individual issues of power and control. The main strength of the team was found in accepting our differences and building on our strengths. An example of this was the Canadian team was highly trained in solution-focused therapy (SFT). This was a skill that was shared by the British nurse but not practiced in some time. The team shared ideas and gave peer supervision regarding using this therapy and developed a more effective joint working environment.

The higher workload appeared to help increase team cohesion. Being in a hospital environment and also being required to travel out to smaller FOBs and COPs, there was a constant workload as the number of ISAF troops increased. Quite simply put, we were 
inundated with one challenging, desperate situation after another. In order to adequately manage in this kind of environment, we needed to pull together for support. This created a shared vision and an ability to provide more care to those who needed it.

As previously mentioned, there was a tension between the need to travel farther forward to meet the needs of those on the smaller FOBs and COPs and the need to maintain enough personnel at Kandahar to manage the increasing stream of patients. We sometimes received requests from forward deployed commanders that we had difficulty meeting. One tactic that worked well was to channel up requests our chains of command to have them engage directly with the forward deployed commanders and determine what the best use of the provider's time would be. They were more aware of the larger situation and helped with prioritizing and negotiating our seemingly conflicting requirements or needs. This took the conflict out of the hands of the providers at KAF, freed them up to continue seeing patients, and helped them manage potential overextension and burn out.

We need to maintain an adequate awareness of multiple theoretical frameworks. Social work students often wonder why they need to be familiar with as many different theoretical frameworks as they are exposed to throughout their undergraduate and graduate educations. This situation serves as a very good model for why we need to have at least a baseline familiarity with these theories. Working in a multi-national, multidisciplinary team illustrates several differences in training. The Canadian and British providers tended to be more versed in solution-focused therapy whereas the US providers were primarily trained in a Cognitive-Behavioral model. Although these models can be quite compatible with one another, it is important to have a baseline understanding of these perspectives so that the providers could better appreciate and support one another while we discussed challenging cases. Clinical feedback may not be as useful if we do not understand the treatment direction and rationale being used by our colleagues.

Along these same lines, baseline knowledge of the mental health disciplines outside of social work is a very useful. In this case, our small team predominantly represented social work but also represented psychiatry, psychiatric nursing, psychology, and a nonlicensed mental health technician. We were not all familiar with what unique expertise each field brought to our team so we spent a good amount of time learning from each other. This knowledge helped us more effectively strategize as a team to meet the everincreasing demand we were facing. Urgency dictated that we focused less on appearing "competent" to one another and instead were open to differing ideas and skill sets. By remaining inquisitive and supportive, we allowed each other to assume more of a learning role without the pressure of having to appear more learned or competent than other members of the team. Because our team was so diverse, we all had questions and knowledge gaps about how to provide the best services we could in this challenging environment. It is important to note that this was the first deployment for the majority of our team and this likely contributed to a greater willingness to ask questions without the fear of appearing incompetent. Given the high turnover rates among military mental health professionals in the US military, the modal number of deployments for any mental health team is likely to be one. Although there are many who have experienced multiple 
deployments, many professionals are on their first deployment while in a combat zone, so openness and a willingness to learn and cooperate are key to success.

As stated above, another lesson we learned was also that we need to understand more about the "in theatre" treatment philosophy of each nation so we could more effectively treat troops from other countries. For example, it is clear that the US highly values mental health treatment in theatre and as a general rule, US forces strive to have a soldier to mental health provider/technician ratio of 1000 to 1 or less. While our team was deployed, Canadians had a similar ratio, although it did not include mental health technicians. The British, on the other hand, had a provider to troop ratio of close to 3000 to 1 . As mentioned earlier, treatment by a mental health provider in theatre is not as highly valued by the British military and the unit is charged with providing the support that is needed to troops who are struggling with mental health symptoms. Clearly, there are differing pressures, expectations, and stigmas within each countries military forces and the providers from each of those military services feel those same pressures. This also requires more flexibility as a mental health provider. Should a US mental health provider approach a British unit in the same manner that would be used with US forces, they risk offending the unit leadership by implying they are not supporting their troops in a satisfactory manner. The ability to properly assess the situation, improvise, and be flexible with our responses proved to be an invaluable skill.

Other differences between countries are that neither Canadians nor the British employ mental health technicians like the US does. The closest equivalent position in Canada is a social service worker. They have completed a two-year college diploma, but are not authorized under health legislation to work in clinical mental health centers. Because of this, the Canadian military does not employ uniformed or civilian social service workers. Not only do the British not have mental health technicians, they do not employ social workers or psychologists as uniformed members of their military. The UK has mental health nurses and psychiatrists. Psychiatrists are generally not deployed, leaving nursing to provide all of the mental health services within theatre.

Perhaps the most important factors contributing to the success of our multi-national relationship towards mental health care work was respect of our differences and a good dose of humor. The team managed to maintain a good sense of humor within this difficult environment while also doing our job under strenuous conditions. The British provider made fun of the fact the Americans and Canadians were required to carry handguns to work while theirs were in the UK armory. The US providers enjoyed poking fun at the way the British tailored their hats to look 'cool'. It was this kind of relationship that enabled the team to gel and work so effectively. In this situation, humor served as a great way to diffuse tensions caused by our challenging mission and helped us develop greater shared bonds.

Though a multiplicity of nations continue to serve at Kandahar, all display the same admirable resilience, dedication, and loyalty to the mission despite their country of origin, extreme conditions, an array of difficulties, and daily challenges. We came to see our clientele not as US, British, or Canadian. Instead, we were all soldiers, engaged as 
one team with one mission. As a cohesive group of mental health providers we were, and continue to be, protective and proud of all who serve.

\section{References}

Department of National Defence Canada. (2009, October 28). The maple leaf. Giving the best care anywhere. Health services made CF history as the lead nation of a multinational medical unit. Retrieved from http://www.forces.gc.ca/site/commun/mlfe/article-eng.asp?id=5705

Department of National Defence Canada. (2010). Surgeon general's report 2010. Retrieved from http://www.forces.gc.ca/health-sante/pub/sgr-rmc-2010/page-15eng.asp

Frappell-Cooke, W., Gulina, M., Green, K., Hacker-Hughes, J., \& Greenberg, N. (2010). Does trauma risk management reduce psychological distress in deployed troops? Occupational Medicine, 60(8), 645-650.

Greenberg, N., Langston, V., Everitt, B., Iversen, A., Fear, N., Jones, N., \& Wessley, S. (2010). A cluster randomised controlled trial to determine the efficacy of Trauma Risk Management (TriM) in a military population. Journal of Traumatic Stress, 23(4), 430-436.

International Security Assistance Force. (n.d.). Retrieved from http://isaf.nato.int

National Institute for Health and Clinical Excellence. (2005, March). Clinical guidelines CG26. Post-traumatic stress disorder (PTSD): The management of PTSD in adults and children in primary and secondary care. Retrieved from http://www.nice.org.uk/CG26

\section{Author's note:}

Address correspondence to Professor Randall Nedegaard, Department of Social Work, University of North Dakota, Gillette Hall Room 306B, 225 Centennial Drive Stop 7135, Grand Forks, ND 58202-7135. E-mail: randy.nedegaard@email.und.edu 